\title{
RICHARD GRAMLICH
}

\author{
Der Urvertrag in der Koranauslegung \\ (zu Sure 7, 172 - 173)
}




\title{
Der Urvertrag in der Koranauslegung (zu Sure 7, 172-173)
}

\author{
Von Richard Gramlich \\ (Freiburg im Br.)
}

Die Verse 172-173 der Sure $A l-a^{\prime} r a \bar{f}$, der siebten Koransure, lauten:

Und als dein Herr von den Kindern Adams, aus ihrem Rücken, ihre Nachkommenschaft herausnahm und sie gegen sich selbst zeugen ließ! (Er sagte:) Bin ich nicht euer Herr? Sie sagten: Ja, wir bezeugen es. Damit ihr (nicht etwa) am Tag der Auferstehung sagt: Wir hatten davon keine Ahnung, oder sagt: Unsere Väter waren bereits früher Polytheisten, und wir sind Nachkommen, nachdem sie nicht mehr da sind. Willst du uns denn zugrunde gehen lassen für die Taten derer, die sich auf Nichtiges einließen?

Die Auslegung dieser Stelle ist weithin, besonders in den Prophetenviten $^{1}$ ) und - in wohl nicht geringem Maß von der Lehre der beherrschenden Bagdader Mystikerpersönlichkeit des Abu l-Qāsim alGunayd (gest. 297/910 oder 298/911) her ${ }^{2}$ ) - in der Sufik, aber auch in der eigentlichen Koranexegese durch die zahlreichen Hadīte belastet, die das darin geschilderte Geschehen in eine Präexistenz zurückverlegen, in der die gesamte zukünftige Menschheit von Gott dem Rücken Adams entnommen und durch die Frage Bin ich nicht euer Herr? und die Antwort Ja vor der irdischen Geburt vertraglich auf das nachgeburtliche Bekenntnis zum alleinigen Herrsein Gottes verpflichtet wurde.

1) Beispiele: Tabarī, $T a^{\prime} r \bar{h} h$ 1, 133-137; Ibn al-Ațīr, Al-kāmil, ed. Beirut, 1, 40-

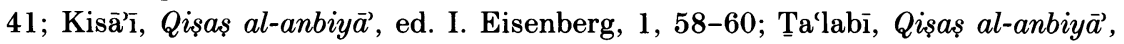
Kairo, Dār ihyyā' al-kutub al-'arabīya, o.J., 34.

$\left.{ }^{2}\right)$ Hierzu vor allem das sog. Kitāb al-mītāaq, in Rasä’ il al-Ğunayd, ed. 'Alī Ḥasan 'Abd al-Qādir: The Life, Personality and Writings of al-Junayd, Gibb Memorial Series, New Series 22, 40-43; auch Kitāb al-fanā’ 32-33; dazu 56-57. Vgl. Sarrāğ, Al-luma', ed. Nicholson, 29-30. Zu beachten ist, daß sich die Sufis weniger für den Vertrag und seinen Inhalt als für die vorgeburtliche Seinsweise bei dem Vertragsschluß interessieren, die als Urbild für die Seinsweise des mystisch Entwordenen dient. 
Ein erheblicher Teil dieser Ḥadīte, deren ursprünglicher Grundgedanke wohl eher nachträglich in unsere Koranstelle hineingetragen als aus ihr herausgelesen wurde, steht in einem dem Wortlaut des Korans nicht entnehmbaren prädestinatianischen Zusammenhang ${ }^{3}$ ), der die Urschöpfung als Akt der Prädestination erscheinen läßt. Das klassische Beispiel: „Man fragte 'Umar b. al-Hattāa nach diesem Vers: Und als dein Herr von den Kindern Adams, aus ihrem Rücken, ihre Nachkommenschaft herausnahm und sie gegen sich selbst zeugen ließ! (Er sagte:) Bin ich nicht euer Herr? Sie sagten: Ja, wir bezeugen es! Damit ihr (nicht etwa) am Tag der Auferstehung sagt: Wir hatten davon keine Ahnung. 'Umar b. al-Hुatțāb antwortete: Ich hörte, wie man den Gesandten Gottes danach fragte. Der Gesandte Gottes antwortete: 'Gott erschuf Adam. Dananch strich er ihm mit seiner Rechten über den Rücken, nahm aus ihm Nachkommen heraus und sprach: Diese habe ich für das Paradies geschaffen; sie werden die Werke der für das Paradies Bestimmten verrichten. Danach strich er ihm über den Rücken, nahm aus ihm Nachkommen heraus und sprach: Diese habe ich für das Höllenfeuer geschaffen; sie werden die Werke der für das Höllenfeuer Bestimmten verrichten.' ... “4)

In seinen zahlreichen Varianten erfuhr das Hadit, abgesehen von seinen vielen prädestinatianischen Erweiterungen und Abwandlungen, noch mancherlei andere konkretisierende Ausschmückungen. Gott nahm eine Handvoll ${ }^{5}$ ); er nahm die für das Paradies Bestimmten mit der Rechten, die für die Hölle Bestimmten mit der Linken ${ }^{6}$ ) - bzw. mit der „anderen“, da beide Hände Gottes Rechte sind ${ }^{7}$ ) - heraus; er strich zuerst über die rechte, dann über die linke Rückenseite ${ }^{8}$ ), oder er schlug Adam zuerst auf die rechte, dann auf die linke Schulter ${ }^{9}$ ); er strich sie heraus wie mit einem Kamm vom $\operatorname{Kopf}^{10}$ ); und schließlich brachte er alle wieder in

3) Zu den Überlieferungsproblemen siehe J. van Ess, Zwischen Hadīt und Theologie 32-39; auch Tabarī 13, Anm. zu Nr. 15357.

$\left.{ }^{4}\right)$ Mālik b. Anas, Al-muwatṭa', ed. Muḥammad Fu'ād 'Abd al-Bāqī, 2, 898-899, qadar 2. Weitere Stellen bei Abū Dāwūd und Tirmidī dort und Wensinck, Concordance 2, 23 a. Dazu Ahmad b. Hanbal, Al-musnad 1, 44-45/1, 289-290, Nr. 311; 'Az̄īmābādī, 'Awn al-ma'būd, ed. 'Abd ar-Raḥmān Muhammad 'Uțmān, 12, 470-472; Tabarī 13, 233-234, Nr. 15357; Tabarī, Ta'rīhn 1, 135-136; Naysābūrī, Al-mustadrak $1,27$.

5) Tabarī 13, Nr. 15344; Tabarī, Ta'rīh 1, 135.

$\left.{ }^{6}\right)$ Tabarī 13, Nr. 15345; 15357; Tabarī Tànih 1, 135-136.

$\left.{ }^{7}\right)$ Tabarī 13, Nr. 15359.

$\left.{ }^{8}\right)$ Tabarī 13, Nr. 15372, nach Suddī. Ebenso Muqātil: Rāzì 15, 46.

9) Tabarī 13, Nr. 15362

$\left.{ }^{10}\right)$ Tabarī 13, Nr. 15354-56; Qurțubī 7, 315 2 . 
Adam hinein ${ }^{11}$ ). Die Urgeschöpfe sind Stäubchen, Mikrowesen $(\underline{d} a r r)^{12}$ ), Senfkörnern gleich ${ }^{13}$ ). Bestimmt werden neben dem ewigen Heil oder Unheil: der Unterhalt ${ }^{14}$ ), das Lebensende und die Schicksalsschläge ${ }^{15}$ ), der Unterhalt sogar in einer Art Vertrag auf Gegenseitigkeit: den Menschen obliegt die monotheistische Gottesverehrung, Gott obliegt der Unterhalt der Menschen ${ }^{16}$ ). Auch den Ort des nachparadiesischen Ereignisses hält man fest: Na'mān ${ }^{17}$ ), Dahnā oder Daḥnā/Dahnnā ${ }^{18}$ ), zwischen Mekka und Tẳif $^{19}$ ), den irdischen Himmel $^{20}$ ).

Das Hadit ist in der islamischen Auslegung von Sure 7, 172-173 für weite Kreise richtungweisend. Doch sind den meisten Exegeten die damit verbundenen Probleme nicht entgangen. Und zwar nicht nur, weil die korrekte Zurückführung des Hadit auf den Propheten gerade in der für die Deutung des Korans grundlegenden Form, in der der Prophet selber als Ausleger des heiligen Textes auftritt, angezweifelt wird ${ }^{21}$ ), sondern weil es sich wenigstens dem äußeren Wortlaut nach nur schwer mit dem Korantext vereinbaren läßt. Daraus ergaben sich Meinungsverschiedenheiten, die von der auf den sogenannten Urvertrag oder Urbund verweisenden, sich streng an die prophetische Überlieferung haltenden Auslegung bis in die kategorische Ablehnung jeder präexistentiellen Deutung reichen. Davon soll hier einiges gezeigt werden. Das Beiwerk - Prophetengeschichten und prädestinatianische Aussagen - bleibt unbeachtet.

Im Gefolge des Hadīt sehen neben den Traditionsgelehrten (ahl al$a h b \bar{a} r$, ahl al-atar $)^{22}$ ) „viele der alten Ausleger, wie Sa ${ }^{(i ̄ d ~ b . ~ a l-M u s a y y i b ~}{ }^{23}$ ),

$\left.{ }^{11}\right)$ Tabarī 13, Nr. 15360, 15362, 15367-68, 15370.

$\left.{ }^{12}\right)$ Tabarī 13, Nr. 15338, 15344, 15348, 15350-51, 15360, 15362, 15365, 15372; Tabarī, Tànīh 1, 133-134; 135, 12; Kulīnī 2, 13.

$\left.{ }^{13}\right)$ Tabarī 13, Nr. 15362.

$\left.{ }^{14}\right)$ Tabarī 13, Nr. 15352.

$\left.{ }^{15}\right)$ Tabarī 13, Nr. 15348-49; Gurğānī 3, 281, 10.

${ }^{16)}$ Tabarī 13, Nr. 15352, 15361.

$\left.{ }^{17}\right)$ Tabarī 13, Nr. 15338, 15340, 15350, 15362; Qurțubī 7, 316, 4.

${ }^{18)}$ Tabarī 13, Nr. 15342, 15347 (mit umstrittener Ortsbezeichnung, s. Anm. zu Nr. 15342).

${ }^{19}$ ) Maqdisī 2, 96; Qurțubī 7, 316, 7-8 (als Meinung Kalbīs).

${ }^{20)}$ Nach Suddī; Qurțubī 7, 316, 8-10.

$\left.{ }^{21}\right)$ Siehe Tabarī 13, Anm. zu Nr. 15357; Qurțubī 7, 315, 5-10; van Ess 36-37.

${ }^{22}$ ) Maqdisī 2, 96, 9-15; Rāzì 15, 46.

${ }^{23}$ ) Abū Muhammad Sa'ìd b. al-Musayyib b. Hazn al-Qurašì (gest. 94/713). Medinensischer Gelehrter und Asket aus der Nachfolgergeneration. 


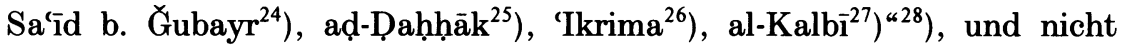
wenige spätere sunnitische und schiitische Exegeten in Sure 7, 172-173 einen Hinweis auf den Urvertrag, den Gott in der Präexistenz mit der gesamten, in Form von Mikrowesen (darr) dem Rücken Adams entnommenen Menschheit geschlossen hat.

Die wichtigste sunnitische Autorität, die den Koranvers urvertraglich deutete, ist der Prophetengenosse 'Abdallāh b. 'Abbās (gest. 68/687 oder wenig später). Seine Auslegung: „Dein Herr strich über den Rücken Adams in der $\mathrm{Na}^{\prime}$ mānniederung da - er deutete mit der Hand hin -, und da kamen alle Menschen heraus, die er bis zum Auferstehungstag erschafft. Er schloß mit ihnen den Vertrag und ließ sie gegen sich selbst zeugen: Bin ich nicht euer Herr? Sie sagten: $\mathrm{Ja}^{\alpha 29}$ ).

Ein kurzes Beispiel aus dem schiitischen Lager hat der Imām Abū Ğa'far Muḥammad al-Bāqir (gest. 114/732) geliefert: „Zurāra ${ }^{30}$ ) sagte: Ich fragte Abū Ga'far nach dem Wort Gottes Und als dein Herr von den Kindern Adams, aus ihrem Rücken, ihre Nachkommenschaft herausnahm und sie gegen sich selbst zeugen ließ! Bin ich nicht euer Herr? Sie sagten: Ja. Er antwortete: 'Er nahm aus dem Rücken Adams seine Nachkommenschaft bis zum Tag der Auferstehung heraus. Sie kamen wie Mikrowesen heraus. Er gab ihnen

${ }^{24}$ ) Abū 'Abdallāh Sa'īd b. Gubayr al-Asadī (hingerichtet durch al-Hağğḡā 95/ 714). Nachfolgergeneration, aus Küfa. Schüler von 'Abdallāh b. 'Abbās (gest. 68/ 687 oder später).

${ }^{25}$ ) Abu l-Qāsim aḍ-Dahḥāâk b. Muzāḥim al-Balḥi al-Ḩurāsānī (gest. um 105/ 723). Hurāsānier, bekannt als Erzieher und Verfasser eines Korankommentars.

${ }^{26}$ ) Abū 'Abdallāh 'Ikrima b. 'Abdallāh al-Barbarī, mawlā Ibn 'Abbās (gest. 105/723 oder später). Vielgereister Koranausleger der Nachfolgergeneration.

${ }^{27}$ ) Abu n-Naḍr Muhammad b. as-Sā'ib al-Kalbī (gest. 146/763), aus Kūfa. Schrieb einen Korankommentar.

$\left.{ }^{28}\right)$ Rāzì 15, 47, 4-5; Naysābūrī 4, 81, 8-9.

${ }^{29}$ ) Tabarī 13, Nr. 15339, mit zahlreichen Varianten danach.

${ }^{30}$ ) Abu l-Ḥasan Zurāra b. A'yan aš-Šaybānī (gest. 150/767-8). Schiitischer Gelehrter aus Kūfa. Zählt zu den wichtigsten Überlieferern der Worte des Imām Muhammad al-Bāqir. Imām Ğa'far aş-Șādiq (gest. 148/765) soll gesagt haben: „Wenn Zurāra nicht wäre, sagte ich: Die Ḥadīte meines Vaters (Muhammad alBāqir) werden verschwinden." Taqī ad-dīn al-Ḥasan b. 'Alī b. Dāwūd al-Ḥillì, $A r$ riğăl, ed. Gaalāl ad-dīn al-Ḥusaynī, Teheran 1383q./1342 s., 156. Mehr bei Kašš̄ī, Ma'rifat ahbār ar-rið̆ăl, Bombay 1317, 88-107/Karbalā' o.J. 121-143. Seine Schule lehrte, Gott sei erst hörend, wissend, sehend geworden, nachdem er diese Eigenschaften für sich erschaffen hatte. Aš́arī, Maqālāt al-islāmīyìn 36; Ibn al-Āīir, $A l$ lubāb, ed. Dār Șādir, Beirut, 2, 63, s.v. Zurārī. 
Erkenntnis und ließ sie sehen. Ohne das würde keiner seinen Herrn erken-

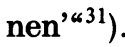

Gegen diese Auslegung des Korantextes im Lichte des Hadīt erhoben sich in erster Linie die Mu'taziliten. Denn, so stellten sie fest, daß Gott die gesamte Nachkommenschaft Adams Rücken entnahm, sagt der Koran gerade nicht. Er sagt nicht: von Adam, sondern von den Kinderm Adams, nicht: aus seinem Rücken, sondern: aus ihrem Rücken, nicht: seine Nachkommenschaft, sondern ihre Nachkommenschaft ${ }^{32}$ ). Zudem legt der Koran dieser Nachkommenschaft die mögliche spätere Entschuldigung Unsere Väter waren bereits früher Polytheisten in den Mund, und das paßt nicht zu den leiblichen Kindern Adams, der ja kein Polytheist war ${ }^{33}$ ).

Den Mu'taziliten schloß sich eine Reihe von Schiiten an. Richtungweisend für die Späteren war Abu l-Qāsim 'Alī b. al-Ḥusayn b. Mūsā, bekannt unter dem Namen aš-Šarī al-Murtaḍa (gest. 436/1044). Er schrieb: „Einige, denen es an Einsicht und Klugheit fehlt, meinten, dieser Vers sei so auszulegen, daß Gott aus dem Rücken Adams dessen ganze Nachkommenschaft als Mikrogeschöpfe herausnahm, sie zwang, anzuerkennen, daß sie ihn erkannten, und sie gegen sich selber zeugen ließ. Darüber hinaus, daß der Verstand diese Auslegung für falsch und unmöglich hält, bezeugt der Wortlaut des Korans das Gegenteil davon. Denn Gott sagte: Und als dein Herr von den Kindern Adams herausnahm, und nicht: von Adam. Und er sagte: aus ihrem Rücken, und nicht: aus seinem Rücken. Und er sagte: ihre Nachkommenschaft, und nicht: seine Nachkommenschaft. Danach tat Gott kund, daß er das getan hat, damit sie nicht am Tag der Auferstehung sagen, daß sie davon keine Ahnung hatten, oder sich damit entschuldigen, daß ihre Väter Polytheisten waren und sie in deren Religion und Herkommen aufgewachsen sind. Das aber erfordert, daß der Vers nicht die leiblichen Kinder Adams betrifft, sondern nur solche, die Väter haben, die Polytheisten waren. Das zeigt, daß sich der Vers nur auf einen Teil der Nachkommenschaft der Kinder Adams bezieht. Das ist das Zeugnis des Wortlauts für die Nichtigkeit ihrer Auslegung ${ }^{\star 34}$ ).

Dem Šrif folgen in ihren Korankommentaren der Šayh aț-țāifa Muhammad b. Hasan aț-Ṭūsī (gest. 459/1067) ${ }^{35}$ ), Abū 'Alī al-Faḍl b. alḤasan aț-Tabrisī (gest. 548/1153) ${ }^{36}$ ), Abu l-futūḥ Gamāl ad-dīn al-Ḥusayn

\footnotetext{
$\left.{ }^{31}\right)$ Kulīnī 2, 13.

${ }^{32)}$ Rāzì 15, 47, huuğğa 1-2; Naysābūrī 9, 81, 20-21.

$\left.{ }^{33}\right)$ Rāzì 15, 47, huğğa 3.

$\left.{ }^{34}\right)$ Murtaḍā 1, 28.

${ }^{35)}$ Tùsī 34, 6-10.

${ }^{36}$ ) Tabrisī 9, 60, 20-61, 2
} 
b. 'Alī b. Muḥammad ar-Rāzì (6./12. Jahrh.; Rayhānat ul-adab 5, 147149) ${ }^{37}$ ), Abu l-Mahāāin al-Ḥusayn b. al-Ḥasan al-Gurğānī (6./12. Jahrh.; Rayhāanat ul-adab 1, 263) ${ }^{38}$ ).

Aber die Mu'taziliten können noch andere koranische Argumente ins Feld führen. So Sure 86, 5-6: Der Mensch möge doch bedenken, aus was er erschaffen ist! Er ist aus hervorquellendem Wasser geschaffen! Sie sagen nach Rāzì: „Wären jene Mikrowesen mit Vernunft, Einsicht und Vollkommenheit ausgestattet gewesen, so hätten sie vor diesem hervorquellenden Wasser existiert. Nun ist aber unter einem Menschen nur das (so mit Vernunft begabte Wesen) zu verstehen. Folglich wäre der Mensch nicht aus dem hervorquellenden Wasser geschaffen. Damit aber widerspricht man dem Text des Korans. - Dem könnte man entgegenhalten: Warum soll man nicht sagen dürfen: Gott hat den Menschen beim Urvertrag vollkommen an Verstand, Vernunft und Fähigkeit erschaffen, dann seinen Verstand, seine Vernunft und seine Fähigkeit wieder beseitigt, um ihn schließlich im Mutterschoß ein zweites Mal zu erschaffen und ihn in dieses Leben hinaustreten zu lassen? Darauf erwidern wir: Das ist falsch. Denn wenn es sich so verhielte, wäre seine Erschaffung aus dem Samentropfen keine erstmalige Erschaffung, sondern müßte eine wiederholte Erschaffung sein. Die Muslime sind sich jedoch darin einig, daß seine Erschaffung aus dem Samentropfen die erstmalige Erschaffung ist. Das beweist, daß ihre Aussage falsch ist“39).

Auf einer ähnlichen Linie bewegt sich die Argumentation mit Sure 23, $12-14^{40}$. Ebenso die folgende Rückführung der Lehre von den präexistentiellen Mikrowesen auf einen Widerspruch zum Koran: „Entweder sagt man, jene Mikrowesen seien mit diesen Menschen hier identisch, oder man sagt, sie seien es nicht. Letzteres ist nach übereinstimmender Meinung falsch. Bleibt das erstere. Wir sagen nun: Entweder sagt man: Sie bleiben, während sie Samentropfen, Embryo und Fötus (Sure 22, 5; 23, 14) sind, mit Vernunft, Verstand und Fähigkeit ausgestattet, oder man sagt: Sie bleiben es nicht. Das erste ist evident falsch. Im zweiten Fall muß man aber sagen: Der Mensch kommt viermal zum Leben: das erste Mal beim Urvertrag, das zweite Mal im Diesseits, das dritte Mal im Grab, das vierte Mal bei der Auferstehung. Und der Tod kommt dreimal zu ihm: Ein Tod nach dem im ersten Bund erhaltenen Leben, ein Tod im Diesseits und ein Tod im Grab. Diese Zahl aber widerspricht der Zahl, die in dem Wort

\footnotetext{
${ }^{37}$ ) Abu l-futūh 9, 325, 18-326, 5.

${ }^{38}$ ) Gưrğānī 3, 284-285.

$\left.{ }^{39}\right)$ Rāzì 15, 49, ḥuğğa 10.

${ }^{40)}$ Rāzì 15, 49, ḥuğğa 12.
} 
Gottes Herr, du hast uns zweimal sterben lassen und zweimal lebendig gemacht (Sure 40, 11) angegeben ist ${ }^{\star 41}$ ).

Diesen Schriftbeweisen der Mu'tazila fügen die Schiiten noch einen weiteren bei. Gestützt auf den Scheich at-țầifa Tūsīin ${ }^{-42}$ schreibt Abu l-futūhọi Rāzī: „Die Nichtigkeit dieser Lehre beweist unter anderem Gottes Wort: Und Gott hat euch aus dem Leib eurer Mutter hervorkommen lassen, ohne daß ihr etwas wußtet (Sure 16, 78). Wenn aber das, was aus dem Leib der Mutter hervorkommt, nichts weiß, dann weiß das, was aus der Lende des Vaters hervorkommt, erst recht nichts ${ }^{443}$ ). Das Unwissende ist natürlich nicht vertragsfähig.

Zentral bleibt die Feststellung, daß das Hadīt vom Urbund dem Text von Sure 7, 172 widerspricht, weil eben die Kinder Adams nicht Adam sind. Gegenüber dieser Schwierigkeit müssen die Ausleger, die - wie im Hadīt des 'Umar der Prophet - das Hadīt als Auslegung des Koranverses betrachten und daher den Vers im Licht des Ḥadīt deuten wollen, irgendwie zeigen, daß der Rücken Adams bei der Erwähnung des Rückens seiner Kinder mitgemeint ist. Ibn al-Ğawzī führt den folgenden Versuch an: „Gott sagte aus ihrem Rücken und nicht: aus dem Rücken Adams, weil (er nur zum Ausdruck bringen wollte, daß) er die einen aus dem Rücken der anderen herausnahm. Daher brauchte er den Rücken Adams nicht zu erwähnen. Denn daß sie seine Kinder und daher aus seinem Rücken herausgenommen sind, weiß man“44). So auch Qurțubī:„Gott erwähnte nicht den Rücken Adams, weil man weiß, daß sie alle seine Kinder sind und am Tag des Urvertrags aus seinem Rücken herausgenommen wurden. Er brauchte ihn also nicht zu erwähnen, weil er sagte: von den Kindern Adams ${ }^{45}$ ).

Faḩr ad-dīn ar-Rāzì (gest. 606/1209) kann auf derartige Künsteleien verzichten. Für ihn behandelt das Hadit eine ganz andere Sache als der Koran. Es kann ihn daher weder auslegen noch bestätigen, noch widerspricht es ihm. „Wenn diese Nachkommenschaft dem Rücken Adams entnommen wäre, hätte Gott gesagt: aus seinem Rücken seine Nachkommenschaft, und nicht aus ihrem Rücken ihre Nachkommenschaft. Dagegen sagen die Verteidiger jener Lehre: 'Der Bericht, der Gesandte Gottes habe diesen Vers auf diese Weise (durch das Geschehnis in der Präexistenz) ausgelegt, ist gesund. Die Auslegung des Gesandten Gottes anzufechten ist

$\left.{ }^{41}\right)$ Rāzì 15, 49, ḥuğğa 11.

$\left.{ }^{42}\right)$ TTùīi 5, 35, 16-18.

$\left.{ }^{43}\right)$ Abu l-futūh 5, 328, 9-12.

$\left.{ }^{44}\right)$ Ibn al-Ğawzī 3, 284, 2-4.

${ }^{45}$ ) Qurțubī 7, 317, 15-17. 
aber nicht möglich.' Wir antworten: Der Wortlaut des Verses besagt, daß Gott die Nachkommenschaft (ich lese ad-durrīyata) den Rücken der Kinder Adams entnommen hat. Das legt man so aus, daß Gott weiß, daß von der und der Person der und der gezeugt wird und von diesem (statt wa-d̄alika

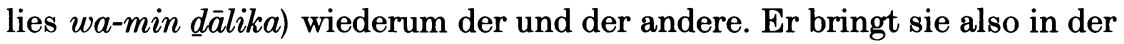
ihm bekannten Reihenfolge ihres Eintritts ins Dasein hinaus und trennt den einen vom anderen. Daß aber Gott diese ganze Nachkommenschaft aus der Lende Adams herausnimmt, darüber steht im Wortlaut des Verses nichts, was es als Tatsache erweist. Es steht aber auch nichts in dem Vers, was es als falsch erweist. Doch der Traditionsbericht spricht dafür. Somit ist das Herausnehmen der Nachkommenschaft aus dem Rücken der Kinder Adams durch den Koran erwiesen und ist das Herausnehmen der Nachkommenschaft aus dem Rücken Adams durch den Traditionsbericht erwiesen. Unter dieser Voraussetzung schließen die beiden Dinge einander nicht aus und widersprechen sich nicht. Man muß sich daher an beides halten, um so, soweit möglich, den Vers und den Bericht vor der Kritik zu schützen. Das ist alles, was man zur Klärung dieses Punktes sagen kann“46). Das gleiche, etwas verkürzt, sagt Niẓām ad-dīn al-Ḥasan b. Muhammad an-Naysābūrī al-A'rağ (gest. 728/1328) ${ }^{47}$ ).

Gegen einen Vertrag in der Präexistenz sprechen neben den Schriftargumenten auch Verstandesbeweise. Vor allem ist es für viele unvorstellbar, daß ein derart gewichtiges Ereignis, das die Menschen, da sie angesprochen wurden und antworteten und für den Vertragsbruch zur Rechenschaft gezogen werden, bei vollem Verstand erlebt haben müssen, von allen ohne Ausnahme vollständig vergessen wurde. Wenn das möglich wäre, könnte man auch die Lehre von der Seelenwanderung nicht widerlegen, da man gegen diese auch nichts anderes als die Unmöglichkeit eines von allen Menschen geteilten totalen Verlustes jeglicher Erinnerung an eine frühere Existenz ins Feld führen kann. So denken die Mu'taziliten ${ }^{48}$ ). Schiitische Ausleger folgen ihnen. Sayyid al-Murtaḍā: „Das Zeugnis des Verstandes beruht auf folgendem: Diese Nachkommenschaft, die (angeblich) aus dem Rücken Adams herausgenommen und danach angesprochen und zum Bekenntnis gezwungen wurde, ist notwendig entweder mit einem vollkommenen Verstand begabt und erfüllt die Bedingungen des religiösen Verpflichtetseins oder sie ist nicht so. Im ersten Fall müssen jene, wenn sie

${ }^{46)}$ Rāzì 15, 51-52.

$\left.{ }^{47}\right)$ Naysābūrī 9, 81, 22-25.

${ }^{48}$ ) Dazu Rāzī 15, 47-48, ḥuğğa 4; auch 48, ḥuğğa 7; Naysābūrī 9, 82, 1-2. Eine Ausnahme ist Sahl at-Tustarī. Er konnte sich an Gottes Frage und sein Ja im Urvertrag erinnern. 'Ațțār, Tadkirat ul-awliyā' 2, 252, 10-12. 
einmal erschaffen und aufgewachsen sind und ihr Verstand vollkommen geworden ist, sich erinnern, was in jenem Zustand mit ihnen vorging und was man sie bekennen und wogegen man sie Zeugnis ablegen ließ. Denn wer bei Verstand ist, vergißt etwas derartiges nicht, auch wenn es vor langer, langer Zeit geschah . . . Zudem wäre es um den in dem Vers enthaltenen $Z$ weck geschehen, wenn man zuließe, daß sie vergessen konnten. Denn Gott tat kund, daß er sie nur zu dem Zweck bekennen und bezeugen ließ, daß sie am Tag der Auferstehung nicht behaupten können, sie hätten davon keine Ahnung und es gebe hierin kein Argument gegen sie. Wenn sie es daher vergessen könnten, folgte daraus, daß das Argument null und nichtig ist. Im zweiten Fall - wenn der Verstand und die Bedingungen für das religiöse Verpflichtetsein nicht gegeben wären - wäre es häßlich, sie anzusprechen und bekennen und bezeugen zu lassen, und die Sache wäre eine häßliche Spielerei. Gott ist darüber erhaben! ${ }^{449}$ )

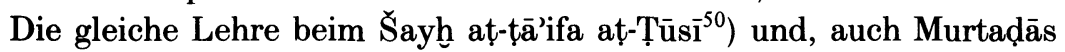
Argumentationsweise angepaßt, bei Abu l-futūḥ-i Rāzì (mit einem Verweis auf die Siebenschläfer, die während 309 Jahren nichts vergaßen) ${ }^{51}$ ), Țabrisī (mit Hinweis auf das Argument gegen die Seelenwanderung) ${ }^{52}$ ) und Gurğān $\left.{ }^{-53}\right)$. Dagegen versuchen die Verteidiger des Urvertrags, diesen als einen Sonderfall darzustellen, auf den andere Erfahrungen mit dem menschlichen Gedächtnis nicht übertragen werden können ${ }^{54}$ ). Oder man zeigt, daß die Erinnerung gar nicht erforderlich ist. Die Exegeten nach Ibn al-Ğawzī: „Dieser Vers ist eine Erinnerung durch Gott an die allen Rechtsfähigen auferlegte vertragliche Verpflichtung und ein Argument gegen sie, damit die Ungläubigen nicht sagen: Wir hatten von diesem Vertrag keine Ahnung und erinnern uns nicht daran. Ihr Vergessen hebt das Argument nicht auf, nachdem Gott dies durch den wahrhaftigen Propheten verkündet hat. Wenn das durch das Wort des Wahrhaftigen feststeht, nimmt es in den Seelen die Stelle des Sicherinnerns ein. Es bleibt also dabei, daß es als Argument dient ${ }^{* 55}$ ).

Qurțubī zitiert Abū Bakr Muhammad b. al-Walīd aţ-Turțūšĩ (gest. 520/ 1126): „Dieser Vertrag ist für die Menschen bindend, wenn sie sich auch in

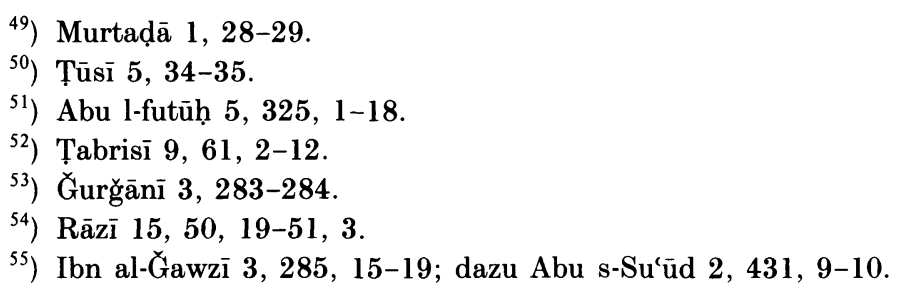


diesem Leben nicht daran erinnern, so wie die Verstoßung durch einen, gegen den sie bezeugt wird, nachdem er sie vergessen hat, bindend ist" ${ }^{\text {"56) }}$ ).

Dem Argument des Mu'taziliten al-Ka' $\mathrm{bi}^{-57}$ ), jener Nachkommenschaft komme nicht mehr Vernunft und Verstand zu als Kindern, und da man einem Kind kein gesetzliches Verpflichtetsein zuspreche, könne man es doch auch jenen Mikrowesen nicht zusprechen, antwortet az-Zağğāğ ${ }^{58}$ ): „Es ist ja nicht ausgeschlossen, daß Gott den Ameisen Verstand verleiht gemäß seinem Wort: Die Ameise sagte: Ihr Ameisen! (Sure 27, 18) - und einem Berg Vernunft gibt, so daß er (Gott) preist - gemäß seinem Wort: Und im Verein mit David machten wir die Berge dienstbar, so daß sie (uns) priesen (Sure 21, 79) -, so wie Gott auch dem Kamel Verstand gegeben hat, so daß es vor dem Gesandten niederfiel ${ }^{59}$ ), und der Dattelpalme, so daß sie hörte und sich lenken ließ, als sie gerufen wurde $\left.{ }^{60}\right)$. So ist es auch hier ${ }^{661}$ ). Al-Ka'bīs Überlegung findet sich auch bei Tūsis ${ }^{-62}$ ). Auch der Hinweis, daß das Denken Leben und Leiblichkeit voraussetze und eine solche Leibermasse, wie sie die der gesamten Menschheit darstelle, ein gigantisches Unding sei, fehlt bei der Mu'tazila nicht ${ }^{63}$ ). Eine andere mu'tazilitische Überlegung: Wenn die Mikrowesen keinen Verstand hatten, konnten sie nicht angesprochen und nicht verpflichtet werden, hatten sie aber Verstand, so waren sie in der gleichen Weise durch die verstandliche Gotteserkenntnis verpflichtet wie die Menschen in diesem Leben. Wenn aber die jetzige Verpflichtung den damaligen Vertrag voraussetzte, setzte auch die damalige Verpflichtung einen weiter zurückliegenden Vertrag voraus. Und so ad infinitum ${ }^{64}$ ).

${ }^{56)}$ Qurțubī 7, 317, 6-7.

${ }^{57)}$ Abu 1-Qāsim 'Abdallāh b. Aḥmad b. Mahmūòd al-Balh̄ī al-Ka'bī (gest. 319/ 931). Mu'tazilitenführer aus Hुurāsān, Schule von Bagdad, Schüler von al-Ḩayyāṭ. Schrieb auch einen Korankommentar. Aḥmad b. Yahyā al-Murtaḍā, Tabaqāt alMu'tazila 88; GAS 1, 622-623.

${ }^{58)}$ Abū Ishạāq Ibrāhīm b. as-Sarī b. Sahl az-Zağğāğ (gest. 311/923). Bagdader Gelehrter.

59) Aḥmad b. Hanbal, Al-musnad, ed. Halabì 6, 76.

${ }^{60}$ ) Ibn Hišàm, As-sīra an-nabawīya, ed. Mușțafā as-Saqqā u.a., Kairo 1375/ 1955, 1, 390-391; Aḥmad Rağab Muhammad, Mu’ ğizāt an-nabī, Kairo 1971, 62-63.

${ }^{61)}$ Rāzì 15, 48, ḥuğğa 8; dazu Naysābūrī 4, 82, 10-16.

${ }^{62)}$ Ṭūsī 5, 34, 5-6.

${ }^{63)}$ Rāzī 15, 48, huuğğa 5-6. Die Hadīte heben deutlich hervor, daß die gesamte künftige Menschheit dem Rücken Adams entnommen wurde: Tabarī 13, Nr. 1533843 ; 15346-47; 15352; 15360; 15370-74; Țabarī, Ta'rỉ 1, 134, 7; 134, 15; 134, 16135,3 .

${ }^{64)}$ Rāzī 15, 48-49, ḥuğğa 9. 
Beiläufig sei hier bemerkt, daß im Kreis der Verfechter des Vertrags in der Präexistenz neben mancherlei anderen auch die Meinung aufkommen konnte, daß das Urbekenntnis der Mikrowesen den unmündig verstorbenen Kindern zum paradiesischen Heil gereiche. Aḍ-Daḥhāk b. Muzāḥim (gest. um 105/723) ${ }^{65}$ ) rechnete daher mit dem jenseitigen Heil seines als Kleinkind verstorbenen Sohnes ${ }^{66}$ ), und einer Nachricht des Mu'taziliten Abu 1-Hudayl al-'Allāf (gest. 226/840 oder später) zufolge soll auch alḤasan al-Başrī (gest. 110/728) den Kleinkindern das Paradies als Lohn für ihren Glauben als Mikrowesen zugesprochen haben ${ }^{67}$ ). Qurțubì, der sich im Kommentar zu Sure 30, 30 ausführlich mit diesen Fragen befaßt hat, bricht für diese These, daß nämlich, „wer als Kind stirbt, wegen seines Bekenntnisses beim ersten Vertrag ins Paradies eingeht" und daher auch entgegen der Lehre des Wahb b. Munabbih (gest. 110/728 oder 114/732), wonach die Kinder der Ungläubigen verlorengehen, weil sie ihr Urbekenntnis nur ungern gesprochen hatten ${ }^{68}$ ) - „die Kinder der Ungläubigen im Paradies sind ${ }^{469}$ ), eine Lanze. Das Kind wird „vom Unglauben unberührt" erschaffen $^{70}$ ). Die Kinder der Muslime werden mit ihren Eltern im Paradies sein, die Kinder der Ungläubigen aber werden nicht mit ihren Eltern sein, ,weil sie im Zustand des ersten Vertrages gestorben sind ${ }^{471}$ ).

Eher am Rande steht auch die Frage, wer die Bezeugenden sind. Nach der großen Mehrzahl der Ausleger ist jeder einzelne Zeuge gegen sich selbst ${ }^{72}$ ). Andere Meinungen: Alle sind gegenseitig Zeugen ${ }^{73}$ ). Die Engel ${ }^{74}$ ) oder Gott und die Engel ${ }^{75}$ ) zeugen gegen die Menschheit. In diesem Fall ist in Sure 7, 172 nicht „Ja, wir bezeugen es" zu lesen, sondern: „Ja!“ „Wir bezeugen es. "Schließlich: Adams Nachkommen und Adam und Himmel und Erde sind Zeugen ${ }^{76}$ ).

$\left.{ }^{65}\right)$ Siehe Anm. 25.

$\left.{ }^{66}\right)$ Tabarī 13, 230-231, Nr. 15352; van Ess 113.

${ }^{67)}$ Ṭūsī 5, 35, 11-12; Tabrisī 9, 61, 16-17; Abu l-futūḥ 5, 328, 7-8.

${ }^{68)}$ Kisā'̂̀, Qişas al-anbiyã $1,60$.

$\left.{ }^{69}\right)$ Qurțubī 7, 317, 8-11.

$\left.{ }^{70}\right)$ Qurțubī 14, 25, 10.

71) Qurțubī 14, 30, $3 \mathrm{ff}$.

$\left.{ }^{72}\right)$ Bayḍāwī 351, 9-12; Zamahš̌arī 176; Abu s-Su'ūd 2, 428-429; Guurğānī 3, 286; Kāšānī 2, 158-159; Fayḍ 1, 624; Tafsīr al-Manār 3, 360.

${ }^{73}$ ) Ibn al-Ğawzì 3, 284, 11; Qurțubī 7, 318, 13-14 (Ibn 'Abbās); Abu l-futūḥ 5, 326, 9-11.

$\left.{ }^{74}\right)$ Rāzī 15, 52, 14-17; Ibn al-Ğawzī 3, 285, 2-3 (al-Kalbī); Qurțubī 7, 318, 912 (Muḡāhid, Dahḥāk, Suddī). Ausdrücklich als falsche opinio: Tūsī 5, 35-36; Tabrisī 9, 62, 19-23; Lāhīḡì 2, 126, 12-20.

${ }^{75}$ ) Ibn al-Ğawzī 3, 284-285 (Suddī).

${ }^{76}$ ) Ibn al-Ğawzī 3, 285, 5-8. (Ubayy b. Ka'b). 
In der ganzen Kontroverse geht es eigentlich nicht, oder doch nur indirekt, darum, was Sure 7, 172-173 sagt, sondern um den Urvertrag mit der in der Präexistenz dem Rücken Adams entnommenen Menschheit. Die eine Partei sieht insbesondere in dieser, aber auch in anderen Koranstellen, eine Widerlegung dieser Vorstellung, die andere nicht, und gegen die den Urvertrag zurückweisenden Verstandesargumente der einen bringen die anderen ihre Gegenargumente. Die eine Partei disqualifiziert - meist stillschweigend - das eingangs erwähnte, bekanntlich wegen seiner obskuren Überlieferung durch Muslim b. Yasār ${ }^{77}$ ) und den gelegentlich dazwischengeschalteten ganz unbekannten Nu'aym b. Rabī $a^{78}$ ) höchst verdächtige Hadīt des 'Umar b. al-Ḩațtāb ${ }^{79}$ ), das den Propheten selbst die Verse im Sinne des präexistentiellen Urvertrags auslegen lä $\mathrm{t}^{80}$ ), die andere verteidigt das Hadīt, oder sie enthält sich einer Stellungnahme zu dessen Verläßlichkeit, da sie sich ja auf viele andere Hadīte zum Urvertrag berufen kann, auch wenn diese nicht den Propheten als Ausleger von Sure 7, 172 vorstellen.

Dem Koranausleger muß sich aber im Hinblick auf den Urvertrag präzis die Frage aufdrängen, die Fahr ad-dīn ar-Rāzī gestellt hat: „Kann man die Lehre vom Urvertrag, gesetzt sie ist richtig, als Auslegung der Worte dieses Verses gelten lassen? ${ }^{481}$ ) Rāzīs Antwort ist ein klares Nein. Der Vers sagt nichts von einem Urvertrag, nichts dafür und nichts dagegen. Das konnte man auch von einem Schiiten hören. Tabrisī vermerkt: 'Alī b. ' $\overline{\mathrm{I}} \mathrm{s} \overline{\mathrm{a}}^{82}$ ) berichtete von Abū Bakr b. al-Ishì ${ }^{83}$ ), er habe den Bericht von den Mikrowesen für möglicherweise gesund gehalten, habe aber gesagt, die Auslegung des Verses gehe nicht davon aus ${ }^{84}$ ).

${ }^{77}$ ) Ibn Sa'd, Ṭabaqāt 7, 1, 120, 8-12.

$\left.{ }^{78}\right)$ Buhārī, At-ta'rīh al-kabìr 4, 2, 96-97; Ibn Abī Hātim ar-Rāzī, Al-ğarh wa-t-

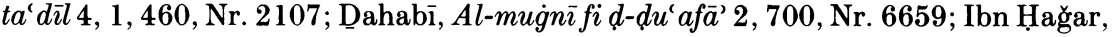
Tahdīib at-Tahdīib 10, 464.

${ }^{79}$ ) Dazu Anm. 21.

${ }^{80}$ ) Allenfalls sollte man noch eine Variante der Ibn 'Abbāsschen Auslegung nennen, die bis auf den Propheten zurückverlängert ist: Tabarī 13, Nr. 15338; dazu für die Schiiten das Ḥadị des Muhammad al-Bāqir: Kulīnī 2, 12-13.

$\left.{ }^{81}\right)$ Rāzì 15, 51, 17-18.

$\left.{ }^{82}\right)$ Abu l-Hasan 'Alī b. 'Īsā ar-Rummānī (gest. 384/994). Mu'tazilit, Philologe, Koranausleger. $\mathrm{GAL}^{2}$ 1, 115; Ziriklì, Al-a' làm 5, 134.

${ }^{83}$ ) Abu Bakr Ahmmad b. 'Alī b. Bayggağūr, bekannt als Ibn al-Išḩīd (gest. 326/ 938). Schiitischer Theologe in Bagdad.

${ }^{84}$ ) Tabrisī 9, 61, 12-14. Auch Ṭūsī 5, 35, 13-14; Abu l-futūḥ 5, 328, 8-9 (wohl mit Druckfehlern beim letzten Namen). Zu Muhammad Bāqir-i Mağlisīs positiver Einstellung zu den Darr-Ḥadīten siehe die Anmerkungen von Mīrzā Abu l-Ḥusayn-i Ša'rānī bei Abu l-futūḥ 5, 326; vgl. Safinnat al-Bihāar 1, 482. 
Was so nur vereinzelt ausdrücklich gesagt wurde, ist dann aber in der exegetischen Praxis weiter Kreise stillschweigend vorausgesetzt worden. Sobald es um die eigentliche Auslegung der Verse - nicht um das Hadīt und seine Varianten und nicht um sein Verhältnis zum Koran - geht, läßt man den Gedanken an den präexistentiellen Urvertrag tatsächlich gern beiseite. Dann ist man sich weitgehend einig, und die Auslegung im Sinne des Urvertrags in der Präexistenz liegt nicht nur den Mu'taziliten fern, sondern ist auch bei Sunniten und Schiiten gleichermaßen die Ausnahme. Die Kinder Adams sind die Menschen, alle Menschen stammen von ihren Vätern ab, alle sind Gott gegenüber durch prophetische Belehrung oder natürliche Gotteserkenntnis verpflichtet. Das etwa ist der gedankliche Rahmen.

Nichts von Adam und seinem Rücken enthält die elementar einfache Auslegung Tabaris (gest. 310/923), nach der die Kinder Adams nicht Adam, sondern den Lenden ihrer Väter entnommen werden: „Denke an deinen Herrn, Muhammad, als er die Kinder Adams aus den Lenden ihrer Väter herausnahm und sie seine Einzigkeit bekennen und einen gegen den anderen bezeugen ließ, daß er das bezeugte und bekannte ${ }^{\star 85}$ ). So denken, wie Maqdisī (schrieb 355/966) ausführt, im Gegensatz zu den auf einen Urvertrag verweisenden Traditionsgelehrten ( $a h l a l$-ahbār), die spekulativen Theologen: „Er schloß diesen Vertrag mit den Kindern Adams, als sie erwachsen und bei voller Verstandeskraft waren. Es gibt keinen Erwachsenen, dem dieses Zeugnis: daß er geschaffen und hervorgebracht ist und einen Schöpfer hat, der, weil er ihn hervorgebracht und ihm Sein verliehen hat, seiner Verehrung würdig ist, nicht klar erkennbar wäre ${ }^{486}$ ).

Auch für Bayḍ̄wīi (gest. 685/1286 oder später) handelt es sich bei dem Entnommenen um Nachkommen, "wie sie nacheinander Generation um Generation geboren werden." Sein Kommentar: „Als dein Herr von den Kindern Adams, aus ihrem Rücken, ihre Nachkommenschaft herausnahm. Das heißt: Er nahm aus ihren Lenden ihre Nachkommen heraus, wie sie nacheinander Generation um Generation geboren werden . . . Und sie gegen sich selbst zeugen ließ: Bin ich nicht euer Herr? Sie sagten: Ja, wir bezeugen es. Das heißt: Er stellte ihnen die Beweise für sein Herrsein auf und bildete in ihrem Verstand etwas, was sie veranlaßte, dieses zu bekennen, so daß sie wie solche wurden, denen man sagte: Bin ich nicht euer Herr?, worauf sie antworteten: $J a$ ! Gott ließ ihre Fähigmachung zur Erkenntnis seines Herrseins und ihr Fähigsein dazu gleichnishaft als Bezeugenlassen und Bekennen gelten. Das zeigt sein Wort: Damit ihr (nicht etwa) am Tag der

\footnotetext{
${ }^{85}$ ) Țabarī 13, 222.

${ }^{86)}$ Maqdisī 2, 96.
} 
Auferstehung sagt: . . . Wir hatten davon keine Ahnung - wir wurden durch keinen Hinweis darauf aufmerksam gemacht - oder sagt: . . Unsere Väter waren bereits früher Polytheisten und wir sind Nachkommen, nachdem sie nicht mehr da sind, und so sind wir ihrem Beispiel gefolgt. Denn wenn der Beweis erbracht ist und die Fähigkeit, ihn zu kennen, gegeben ist, ist die Nachahmung keine gültige Entschuldigung ${ }^{487}$ ).

Qurţubī referiert die folgende Ansicht: „Manche lehren, der Vers bedeute: Gott nahm aus dem Rücken der Kinder Adams die einen nach den anderen heraus. Er ließ sie gegen sich selbst zeugen: Bin ich nicht euer Herr? bedeute: Er führte sie durch seine Schöpfung zum Bekenntnis seiner Einheit, da jeder Erwachsene mit Notwendigkeit weiß, daß er einen einzigen Herrn hat. Er sagte: Bin ich nicht euer Herr? Das ist gleichbedeutend damit, daß er sie gegen sich selbst zeugen ließ und sie bekannten, so wie Gott auch über Himmel und Erde gesagt hat: Sie sagten: Wir kommen freiwillig (Sure 41, 11).“ Als Vertreter dieser Lehre nennt Qurțubī den Tabarīschüler Abū Bakr Muhammad b. 'Alī b. Ismāîl aš-Šāšì al-Qaffāl (gest. 365/976) ${ }^{88}$ ).

Daß Gott die Nachkommen aus den Lenden der Kinder Adams herausnimmt und Zeugnis geben läßt, bedeutet nach Ibn Katīir (gest. 774/1373): Er hat alle Menschen in der hanīfischen Urnatur (fitra), als Monotheisten ('ala t-tawhìd) erschaffen, und das nicht in der Präexistenz. „Er nahm die Nachkommenschaft der Kinder Adams aus deren Lenden heraus, indes sie gegen sich selbst bezeugten, daß Gott ihr Herr und Eigentümer ist und daß es keinen Gott gibt außer ihm, da er sie ja in diesem Zustand erschaffen und gebildet hat. Er sprach: Richte dein Antlitz auf die Religion als Hañ̄f! Das ist die Umatur, in der Gott die Menschen erschaffen hat. Die Art und Weise, in der Gott (die Menschen) geschaffen hat, kann man nicht abändern (Sure 30, $\left.30)^{(89}\right)$. - Danach folgen Hadīte 1. zur Erschaffung 'ala l-fițra (2, 261), 2. zum Urbekenntnis und zum Urvertrag in der Präexistenz (2, 261-262), 3. zur Prädestination in der Präexistenz (2, 262-264). Sodann stellt Ibn Katīir fest, daß die verläßlichen unter den auf die Präexistenz verweisenden Hadīten alle prädestinatianisch sind, während die Hadīte von Urbekenntnis und Urvertrag nicht bis auf den Propheten zurückgehen (2, 264, 3-5), und fährt dann fort: „Daher haben Vertreter der Altvordern und der Späteren gesagt: Mit diesem Bezeugenlassen ist nichts als ihre Erschaffung im Einheitsbekenntnis ('ala t-tawhīd) gemeint . . . Sie sagten: Daher sagte Gott: Und als dein Herr von den Kindern Adams herausnahm, und nicht:

\footnotetext{
${ }^{87)}$ Bayḍāwī 1, 351.

${ }^{88)}$ ) Qurțubī 7, 314, 7-11.

${ }^{89}$ ) Ibn Katīir 2, 261.
} 
von Adam, aus ihrem Rücken, und nicht: aus seinem Rücken. Ihre Nachkommenschaft, das heißt: Er hat ihre Nachkommen Volk nach Volk und Generation nach Generation eingesetzt. So hat er auch gesagt: Er ist es, der euch als Nachfolger (früherer Generationen) auf der Erde eingesetzt hat (Sure 35, 39), und: und setzt euch als Nachfolger (früherer Generationen) auf der Erde ein (Sure 27, 62), und: so wie er euch als Nachkommenschaft von anderen Leuten hat entstehen lassen (Sure 6, 133). Dann sprach er: Und er ließ sie gegen sich selbst zeugen: Bin ich nicht euer Herr? Sie sagten: Ja! Das heißt: Er hat sie dies bezeugend, es durch Zustand und Wort sagend, ins Dasein gebracht $\ldots{ }^{90}$ ) Daß dies damit gemeint ist, wird dadurch bewiesen, daß Gott dieses Bezeugen bezüglich der Vielgötterei zu einem Argument gegen sie gemacht hat. Wenn aber das so (in der Präexistenz) stattgefunden hätte, wie manche es behaupten, dann würde jeder sich daran erinnern (müssen), damit es als Argument gegen ihn dienen kann. Wenn man aber einwendet: 'Daß der Gesandte es kundgetan hat, beweist zur Genüge, daß es so ist (auch wenn sich keiner daran erinnert)', so ist zu antworten: Die Leugner unter den Polytheisten leugnen alles, was die Gesandten gebracht haben, sowohl das als auch anderes. Das aber ist noch ein besonderer Beweis gegen sie. Es zeigt, daß das Gemeinte die ihnen anerschaffene, im Bekenntnis zur Einzigkeit Gottes bestehende Urnatur ist. Darum sprach Gott: Damit ihr - das heißt: damit ihr nicht etwa - am Tag der Auferstehung sagt: Wir hatten davon - vom Einheitsbekenntnis - keine Ahnung, oder sagt: Unsere Väter waren Polytheisten usw. ${ }^{\text {"91) }) .}$

Auch Abu s-Su'ūd al-'Imādī (gest. 982/1574) erkannte in der Koranstelle einen bildlichen Ausdruck, der besagt: „Gott hat alle Menschen in der Urnatur (fitra) mit der Anlage geschaffen, Erkenntnis zu gewinnen aus den in der weiten Welt und in ihnen selbst aufgerichteten, zum Einheitsbekenntnis und zum Islam führenden Beweisen, wie der Prophet gesagt hat in seinem Wort: Jeder, der geboren wird, wird in der Urnatur geboren" ${ }^{\text {“92 }}$ ). Im einzelnen: Gott gibt den Menschen die Fähigkeit, ihn als Herrn zu erkennen, indem er ihnen den Verstand und die überall sichtbaren Beweise gibt, und liefert sie dieser Erkenntnis aus und veranlaßt sie damit, sich zu ihr zu bekennen, „ohne daß es da Vertragschluß und Bezeugenlassen und Frage und Antwort gäbe ${ }^{\alpha 33}$ ).

$\left.{ }^{90}\right)$ In einem Einschub erklärt hier Ibn Katīir, wie man nicht nur durch das, was man sagt, seine Worte, sondern auch durch das, was man ist, seinen Zustand, etwas aussagen kann.

${ }^{91)}$ Ibn Katīr 2, 264, 5-18.

${ }^{92}$ ) Berühmtes Prophetenwort mit zahlreichen Varianten. Wensinck, Concordance 5, 179-180, s. v. fitra.

$\left.{ }^{93}\right) \mathrm{Abu} \mathrm{s-Su}$ 'ùd 2, 429, 8-16. 
Ebenfalls im Sinne einer Schöpfung in der monotheistischen Urnatur wird der Vers im Tafsīr al-Manār gedeutet: „Erinnere dich, Gesandter, nachdem erwähnt wurde, daß der Bund der Inspiration mit den Israeliten im besonderen geschlossen wurde, des Bundes der Urnatur und der Vernunft, den Gott mit der Menschheit im allgemeinen geschlossen hat, da er aus den Kindern Adams ihre Nachkommenschaft Geburt nach Geburt herausgenommen hat. Gott hat sie in der Urnatur des Islams erschaffen und die natürliche Anlage des Glaubens in sie hineingelegt, und er ließ ihren Verstand die Notwendigkeit erfassen, daß jede Wirkung notwendig ein Bewirkendes und jedes Entstehende notwendig ein Hervorbringendes voraussetzt und daß es über den kontingenten Welten, die auf dem Gesetz (sunna) der Ursachen und Wirkungen gegründet sind, einen höchsten Herrscher über alles Seiende gibt. Er ist der Erste und der Letzte (Sure 50, 15), er ist der allein der Verehrung Würdige ${ }^{494}$ ).

Bei den Mu'taziliten ist eine nachgeburtliche Auslegung zu erwarten. Beispiele liefert uns Țūsī: „Al-Balh ${ }^{-95}$ ) und ar-Rummänīi ${ }^{96}$ ) sagten: Er meinte damit die Volljährigen unter den Kindern Adams und daß er sie als Nachkommenschaft Generation um Generation und Zeitalter nach Zeitalter herausnahm und sie gegen sich bezeugen ließ, daß er sie ins reife Alter gebracht und mit einem vollkommenen Verstand ausgestattet hat und in ihnen Beweise aufgestellt hat, die zeigen, daß sie geschaffen sind und das Geschaffene notwendig auf einen Erschaffer angewiesen ist ... Und (er ließ sie Zeugnis ablegen für) die Bestätigungen dafür und die Anspornungen, darüber nachzudenken, die er ihrem Herzen eingab; sodann, daß er die Gesandten geschickt und die heiligen Bücher herabgesandt hat, damit sie, wenn sie die Strafe erfahren, nicht sagen: 'Wir hatten davon keine Ahnung. Man gab uns davon keine Kenntnis (ich lese lam nunabbah 'alayh) und lieferte kein Argument dafür, und unser Verstand war nicht vollendet, so daß wir darüber hätten nachdenken können', oder manche von ihnen sagen: 'Unsere Väter waren Polytheisten, als sie in reifem Alter standen und Verstand besaßen. Wir jedoch waren Kinder ohne Verstand und nicht befähigt zum Denken, Überlegen und Planen.' - AlGubbā ${ }^{2-97}$ ) sagte: Daß er ihre Nachkommenschaft aus ihrem Rücken herausnahm besagt: Er hat sie als Samentropfen aus dem Rücken der Väter und dann im Schoß der Mütter erschaffen, dann hat er sie von

${ }^{94)}$ Tafsìr al-Manār ${ }^{2}$ 9, 360.

$\left.{ }^{95}\right)$ Siehe Anm. 57.

$\left.{ }^{96}\right)$ Siehe Anm. 82.

${ }^{97}$ ) Abū 'Alì Muhammad b. 'Abd al-Wahhāb b. Salām al-Ğubbā'ì (gest. 303/ 915-16), der bekannte Bașrische Mu'tazilit. 
Beschaffenheit zu Beschaffenheit und von Form zu Form gebracht, dann wurden sie zu Lebewesen, indem Gott ihnen im Mutterleib Leben verlieh und ihre Schöpfung vollendete, dann hat er sie durch die Geburt aus dem Mutterleib herausgenommen ${ }^{498}$ ).

Nun die Schiiten: Der Šrīf al-Murtaḍā läßt zwei Deutungen zu: Bund durch prophetische Belehrung oder durch natürliche Erkenntnis. „Wenn man nun sagt: 'Ihr habt die Auslegung eurer Gegner widerlegt. Doch was ist nach eurer Ansicht die richtige Auslegung des Verses?', so antworten wir: Bei diesem Vers gibt es zwei Möglichkeiten. Erstens: Gott meinte aus der Nachkommenschaft der Kinder Adams nur eine Anzahl Leute, die er erschuf, ins reife Alter kommen ließ und mit einem vollkommenen Verstand ausstattete und durch die Zungen seiner Gesandten nötigte, ihre Gotteserkenntnis und Gehorsamspflicht gegenüber Gott anzuerkennen, und die dies dann anerkannten und damit gegen sich selbst zeugten, damit sie nicht am Tag der Auferstehung sagen: Wir hatten davon keine Ahnung oder sich damit entschuldigen, daß ihre Väter Polytheisten waren ... Die zweite Antwort. Indem Gott sie erschuf und in einer solchen Weise bildete, daß das zu seiner Erkenntnis führt und seine Allmacht und die Pflicht, ihm zu dienen, bezeugt, und er ihnen die Belehrung und Zeichen und Beweise in ihnen selbst und anderswo zeigte, ließ er sie gleichsam gegen sich selber zeugen. Und indem sie das sahen und erkannten und es sich ihnen so zeigte, wie Gott es wollte, und es für sie ausgeschlossen war, sich dem zu verschließen und sich seiner Beweiskraft zu entziehen, haben sie gleichsam anerkannt und bekannt, obgleich es da kein wirkliches Bezeugen und Bekennen gab. Das ist ähnlich wie das Wort Gottes: Hiernach richtete er sich zum Himmel auf, der aus Rauch bestand, und sagte zu ihm und zur Erde: Kommt her, freiwillig oder widerwillig! Sie sagten: Wir kommen freiwillig (Sure 41, 11), obwohl Gott in Wirklichkeit nicht sprach und sie nicht antworteten. So ist auch das Wort Gottes: wo sie doch gegen sich selber bezeugen, daß sie ungläubig sind (Sure 9, 17). Dabei wissen wir, daß die Ungläubigen ihren Unglauben nicht mit der Zunge eingestanden haben. Doch indem er sich an ihnen mit einer für sie unabweisbaren Deutlichkeit zeigte, haben sie ihn gleichsam eingestanden. So sagt man auch: Meine Glieder bezeugen deine Güte, mein Zustand bekennt deine Wohltat . . ." ${ }^{\circ 99}$ ).

Abu l-futūḥ-i Rāzi ${ }^{-100}$ ) und Abu l-mahāāsin-i Gurğānīi ${ }^{101}$ ) schließen sich, den Text etwas erweiternd, eng an den Šarif an.

\footnotetext{
${ }^{98}$ ) Tũsī 5, 32-33.

99) Murtaḍā 1, 29-30.

100) Abu l-futūḥ 5, 326, 6-327, 11.

101) Gurḡānī 3, 284-286.
} 
Țūsī hat die prophetische Belehrung im Auge. „Mit seinem Wort Er ließ sie gegen sich selbst zeugen ist gemeint: Als sie in reifem Alter standen und bei vollem Verstand waren und sie ihren Herrn erkannt hatten und er sie durch einen seiner Propheten fragen ließ: Bin ich nicht euer Herr?, worauf sie antworteten: Ja, wir bezeugen es!, da sie erkannt hatten, daß Gott ihr Herr ist. Sein Wort Damit ihr sagt: Wir hatten davon keine Ahnung bedeutet: Damit ihr am Tag der Auferstehung nicht sagt: Wir hatten davon keine Ahnung. Damit meint er: Ich habe euch das bekennen lassen, damit ihr im Gehorsam gegen mich verharrt und für meine Wohltat Dank erweist und am Auferstehungstag nicht sagt: Wir hatten davon keine Ahnung. Sein Wort: Oder sagt: 'Unsere Väter waren bereits früher Polytheisten, und wir sind Nachkommen, nachdem sie nicht mehr da sind. Wir sind in ihrer Vielgötterei aufgewachsen' und damit am Tag der Auferstehung argumentiert. Es ist klar, daß ich damit dieses euer Argument dadurch zunichte gemacht habe, daß ich euch nötigte, zu bekennen, daß ihr mich kennt, und euch gegen euch selbst bezeugen ließ, daß ihr mich zu kennen bekannt habt“"102).

Tabrisī nennt drei Auslegungen: Mikrowesen, natürliche Erkenntnis, prophetische Belehrung. Die Lehre von den Adam entnommenen Mikrowesen lehnt er ab. Zu den beiden anderen bemerkt er: „Zweitens. Mit dem Vers ist gemeint: Gott nahm die Kinder Adams aus den Lenden ihrer Väter heraus in den Schoß ihrer Mütter. Dann ließ er sie sich Stufe um Stufe weiterentwickeln, zu einem Embryo, dann einem Fötus. Dann bildete er einen jeden davon zu einem wohlgestalteten Menschen, dann einem rechtsfähigen Lebewesen. Er ließ sie die Wirkungen seiner Schöpfertat sehen und befähigte sie, seine Beweise zu erkennen, so daß er sie gleichsam bezeugen ließ und zu ihnen sagte: Bin ich nicht euer Herr?, worauf sie sagten: $J a$ ! Das ist der Sinn von Er ließ sie gegen sich selbst zeugen. Er wies sie durch seine Schöpfung auf seine Einzigkeit hin. Er ließ sie dadurch gegen sich selbst zeugen, weil er in ihren Verstand auf seine Alleinheit verweisende Beweise gelegt und darin und in anderem Wunder seiner Schöpfung und staunenerregende Werke seines Schöpferwirkens gebildet hat. So ist er gleichsam einer, der sie gegen sich selbst zeugen läßt. Und so sind sie, wenn sie das betrachten und es sich an ihnen zeigt, wie Gott es will, und sie sich nicht ihm entziehen können, gleichsam Zustimmende und Bekennende, obgleich es da weder der äußeren Form noch der inneren Wirklichkeit nach ein Bezeugenlassen gibt ... Das lehren ar-Rummānīina), Abū

${ }^{102)}$ Ṭūsī 5, 33.

103) Siehe Anm. 82. 
Muslim $^{104}$ ) und Ibn al-Išhīi ${ }^{105}$ ). - Drittens. Gott meinte damit aus der Nachkommenschaft Adams nur eine Gruppe. Diese erschuf er und stattete sie mit einem vollkommenen Verstand aus und zwang sie, auf das Wort seiner Propheten hin ihre Erkenntnis Gottes und ihre Gehorsamspflicht gegen ihn einzugestehen. Daher bekannten sie das, und er ließ sie gegen sich selbst zeugen, damit sie nicht am Tag der Auferstehung sagen: Wir hatten davon keine Ahnung, oder sagen: Unsere Väter waren bereits früher Polytheisten, wir haben sie darin nachgeahmt. Gott wies darauf hin, daß er keinen straft, der eine Entschuldigung hat, als ein Erbarmen und einen Hulderweis gegenüber seinen Geschöpfen. Das betrifft nur bestimmte Leute unter den Kindern Adams. Sie zählen nicht alle dazu. Die Gläubigen zählen nämlich nicht dazu. Denn es ist klar, daß jene in Vertrag Genommenen polytheistische Vorfahren hatten. Und die leiblichen Kinder Adams wurden nicht aus den Rücken der Kinder Adams genommen. Sie gehören

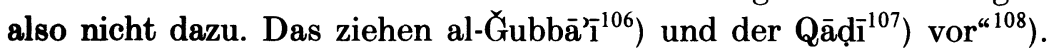

Die Gegner der urvertraglichen Auslegung machen wie Țabrisī in dem eben zitierten Text auch sonst gelegentlich darauf aufmerksam, „daß sich der Vers nur auf einen Teil der Nachkommenschaft der Kinder Adams bezieht $^{\star 109}$ ). Tūsī: „Sein Wort: Willst du uns denn zugrunde gehen lassen für die Taten derer von unseren Vätern, die sich auf Nichtiges einließen? Das zeigt, daß der Vers speziell für gewisse Leute unter den Kindern Adams gilt und nicht für alle. Denn nicht alle Kinder Adams wurden aus dem Rücken der Kinder Adams herausgenommen, da man von den leiblichen Kindern Adams nicht sagen kann, sie seien aus dem Rücken der Kinder Adams herausgenommen worden. Somit sind Adams leibliche Kinder davon ausgenommen. Ebenso sind sie Kinder der Gläubigen unter den Nachkommen Adams, deren Väter keine Polytheisten waren, ausgenommen. Denn es ist klar, daß diese, die sich zur Gotteserkenntnis bekannten und diesbezüglich in Vertrag genommen wurden, Vorfahren hatten, die Polytheisten waren. Dadurch ist erwiesen, daß es sich bei ihnen um bestimmte Leute aus den Kindern Adams handelt ${ }^{\star 110}$ ). Man stellt fest: „Gott sprach:

${ }^{104}$ ) Abū Muslim Muhammad b. Baḥr al-Ișfahānī (gest. 322/934). GAS 1, 4243; Ziriklī, Al-a'lām 6, 273.

105) Siehe Anm. 83.

106) Siehe Anm. 97.

$\left.{ }^{107}\right)$ Der berühmte Mu'tazilit Abu l-Hasan 'Abd al-Ğabbār b. Aḥmad b. 'Abd al-

Gabbār al-Hamadānī al-Asadābādī al-Mu'tazilī al-Qādị̄, gest. 415/1025 in Rayy.

${ }^{108)}$ Tabrisī 9, 61, 18-62, 19.

109) Murtaḍā 1, 28.

$\left.{ }^{110}\right)$ Tūsī 5, 33-34. 
von den Kindern Adams, aus ihrem Rücken. Die leiblichen Kinder Adams gehören also nicht dazu (zu den Herausgenommenen). Und er sprach: oder sagt: Unsere Väter waren bereits früher Polytheisten. Somit sind alle, die keine polytheistischen Väter hatten, nicht einbezogen. Man sagt auch: Der Vers betrifft ausschließlich jene, die durch das Wort der Propheten vertraglich verpflichtet wurden" ${ }^{111}$ ). Die Einschränkung kann so verstanden werden, daß das Gotteswort sich speziell an die Juden richtet. Baydāwī: „Daß Gott dieses Wort an diese Stelle gesetzt hat, hat den Zweck, die Juden (erstens) an die Forderung des allgemeinen Vertrages (mit der ganzen Menschheit) zu binden, nachdem er sie an den ihnen zubestimmten besonderen Vertrag gebunden hatte ${ }^{112}$ ), (zweitens) gegen sie Überlieferungs- und Verstandesargumente vorzubringen, (drittens) sie vom Nachahmen abzuhalten und (viertens) sie dazu zu bewegen, nachzudenken und Schlüsse zu ziehen “113). Oder man versteht unter den Kindern Adams die polytheistischen Vorfahren der Juden. Zamahšarī: „Wenn du fragst: Wer sind die Kinder Adams und ihre Nachkommenschaft?, so antworte ich: Mit den Kindern Adams sind die Vorfahren der Juden gemeint, die Polytheisten waren, da sie sagten: 'Uzayr ist der Sohn Gottes (Sure 9, 30), und mit ihrer Nachkommenschaft die, die zur Zeit des Propheten zu ihren Nachfolgern, die dem Beispiel ihrer Väter folgten, gehörten. Der Beweis, daß der Vers die Polytheisten und ihre Kinder betrifft, ist Gottes Wort: oder sagt: Unsere Väter waren bereits früher Polytheisten, der Beweis, daß er die Juden betrifft, sind die (die Juden betreffenden) Verse, an die er sich anlehnt, und die Verse, die sich an ihn anlehnen, indes diese seiner Art entsprechen, nämlich Gottes Wort: Und frag sie nach der Stadt (Sure 7, 163), Und als eine Gemeinschaft von ihnen sagte: Warum ermahnt ihr? (Sure 7, 164), Und als dein Herr ankündigte (Sure 7, 167), Und verlies ihnen die Geschichte von dem, dem wir unsere Zeichen gaben (Sure 7, 175) “114).

Den vielen Vertretern einer nachgeburtlichen Auslegung widerspricht unter den bekannteren Exegeten, deren Werke noch heute zugänglich sind, eine eher kleine Schar. Ein entschiedenes Wort zugunsten des Urvertrags mit den Mikrowesen in der Präexistenz hat Ibn Qutayba (gest. 276/886) gesprochen. Zunächst bringt er das Argument der Gegner: „Ihr habt berichtet: Gott strich über den Rücken Adams, holte daraus seine Nachkommenschaft bis zum Tag der Auferstehung wie Mikrowesen hervor und ließ sie gegen sich selbst zeugen: Bin ich nicht euer Herr? Sie sagten: Ja. Das

111) Qurțubī 7, 316-317.

112) Dazu der vorausgehende Vers Sure 7, 171.

113) Baydōāīi 1, 351.

$\left.{ }^{114}\right)$ Zamahšarī 2, 177. 
widerspricht dem Wort Gottes: Und als dein Herr von den Kindern Adams, aus ihrem Rücken, ihre Nachkommenschaft herausnahm und sie gegen sich selbst zeugen ließ! (Er sagte:) Bin ich nicht euer Herr? Sie sagten: Ja! Denn das Hadit sagt, er habe aus dem Rücken Adams herausgenommen, das Heilige Buch aber sagt, er habe aus dem Rücken der Kinder Adams herausgenommen.“ Darauf antwortet er: „Es verhält sich nicht so wie sie meinen. Vielmehr stimmt beides inhaltlich überein und ist in Ordnung. Denn das Heilige Buch bringt Sätze, die das Hadīt einschließt, und eine Zusammenfassung, auf die der Heilige Brauch hinweist. Siehst du denn nicht, daß damals, als Gott, wie das Hadīt berichtet, den Rücken Adams rieb und dessen Nachkommenschaft wie Mikrowesen bis zum Tag der Auferstehung daraus herausnahm, unter dieser Nachkommenschaft die Söhne und die Söhne der Söhne und deren Söhne bis zum Tag der Auferstehung waren? Wenn er aber mit allen diesen den Vertrag schloß und sie gegen sich selbst zeugen ließ, dann hat er von sämtlichen Kindern Adams, aus ihren Rücken, ihre Nachkommenschaft herausgenommen und gegen sich selbst zeugen lassen. Dem ähnlich ist Gottes Wort in seinem Buch: Und wir haben euch doch geschaffen, dann gestaltet, dann haben wir zu den Engeln gesagt: Werft euch vor Adam nieder! (Sure 7,11). Er stellte sein Wort an die Engel Werft euch vor Adam nieder hinter Wir haben euch geschaffen und Wir haben euch gestaltet. Er meinte nämlich mit seinem Wort Wir haben euch geschaffen und Wir haben euch gestaltet: Wir haben Adam geschaffen und ihn gestaltet, dann haben wir zu den Engeln gesagt: Werft euch vor Adam nieder! Das ist möglich; denn als Gott Adam erschuf, erschuf er uns in seinen Lenden und bildete uns, wie er wollte. So hat er die Erschaffung Adams als unsere Erschaffung bezeichnet, da wir zu ihm gehören ${ }^{115}$ ).

Ibn al-Ğawzī verwirft die nachgeburtliche Auslegung nicht, hält aber die urvertragliche Sicht für gesünder. „Eine Anzahl Gelehrter vertritt die von uns dargelegte Ansicht, daß Gott die Mikrowesen zum Sprechen brachte und in ihnen Verstand und Erkenntnisvermögen gebildet hat, womit sie erkennen, was ihnen gezeigt wird. Andere von ihnen haben gesagt: Das Herausnehmen der Nachkommenschaft bedeutet ihre Hinausführung in das Diesseits, nachdem sie Samentropfen gewesen waren, und das gegen sich selbst Bezeugenlassen bedeutet, daß sie durch die Zeichen und Beweise, die er ihnen zeigte, gezwungen waren, zu erkennen, daß er ihr Schöpfer ist. Und nachdem sie das erkannt hatten und alles, was sie sahen und erblickten, sie zur Zustimmung bewegte, waren sie gleichsam Anwe-

$\left.{ }^{115}\right)$ Ibn Qutayba, Ta'wīl muhtalif al-hadīt, ed. Muhammad Zuhrī an-Nağğār, Kairo 1386/1966, 87-88. Vom Sarī al-Murtadāa ausdrücklich zurückgewiesen: $A l$ amālī 2, 86. 
sende und gegen sich selber dessen Tatsächlichkeit Bezeugende . . . Eine derartige Lehre hat Ibn al-Anbārīi ${ }^{-16}$ ) übermittelt. Das erste ist gesünder, weil die Überlieferungen damit übereinstimmen ${ }^{\text {“117). }}$.

Noch ein Beispiel aus dem Kreis der späteren Schia. Bahä' ud-dīn (alias Quṭb ud-dīn) Muhammad b. Šayh'alīi Šarīfi Lāhīḡĩ (11./17. Jahrh.) verteidigte energisch den Urvertrag in der Präexistenz. Im Kommentar zu Sure 7, 172 schrieb er: „Dieses Herausnehmen der Kinder Adams aus ihren Rücken und Lenden geschah zu einer Zeit, als alle noch in der Lende Adams waren. Gott hat also die Nachkommenschaft der Kinder Adams, die in Wirklichkeit die Nachkommen Adams aus ihren Lenden sind, aus der Lende Adams herausgenommen. Daß Gott gesagt hat, die Nachkommen der Kinder Adams habe der Schöpfer der Welt aus deren Rücken herausgenommen, steht nicht in Widerspruch dazu, daß dieses Herausnehmen aus der Lende Adams geschah. Adam blieb deshalb unerwähnt, weil jedermann weiß, daß Adam der Ausgangspunkt aller Nachkommen und die Summe dieser Einzeldinge ist. Der Schöpfer hat diese Nachkommen in Gestalt winziger Ameisen ( $m \bar{u} r c ̌ a g \bar{a} n$ ) aus dem Rücken Adams herausgenommen und in ihnen die Verstandeskraft hinterlegt und sie erkenntnisfähig gemacht, so daß sie imstande waren zu sprechen und zu bezeugen gemäß Gottes Wort und sie bezeugen ließ . . . Diese Auslegung haben alle Mu'taziliten, wie Fahr-i Rāzī gezeigt hat, und unter denen, die zur Schar der Geretteten zählen (den Schiiten), Sayyid al-Murtaḍā, strikt abgelehnt und sich dabei auf einige Verstandesargumente gestützt. Doch zeigt sich klar und deutlich, daß die meisten davon auf Grund der Worte unserer Auslegung in sich zusammenstürzen. Diese Leugner haben den Vers so ausgelegt: Erinnere dich, Muhammad, als dein Schöpfer aus den Lenden der Kinder Adams ihre Nachkommenschaft Generation um Generation herausnahm und sie gegen sich zeugen ließ in dem Sinn, daß er für sie die Beweise seines Herrseins erbrachte und sie das Herrsein des Herrn der Menschen mit absoluter Sicherheit erkannten, dergestalt, daß er gleichsam zu ihnen sagte: Bin ich nicht euer Herr? und sie antworteten: Ja! Sodann hat Gott ihre Gewißheit über das Herrsein des Herrn der Menschen als Bezeugung gelten lassen und gleichnishaft gesagt: und er ließ sie gegen sich selbst zeugen. Diese Auslegung widerspricht dem Wortlaut der Überlieferungen ${ }^{* 118}$ ).

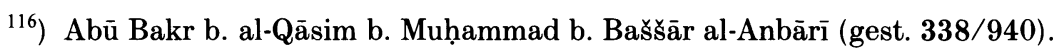
Bedeutender Philologe und Koranausleger. GAL ${ }^{2}$ 1, 122-123; Ziriklī, Al-a lām 7, 226-227.

$\left.{ }^{117}\right)$ Ibn al-Gawzì 3, 286.

$\left.{ }^{118}\right)$ Tafsìr-i Šarīf-i Lāhì̆ğ, ed. Ğalāl ud-dīn-i Ḥusaynī-i Armawī, Teheran 1381q./1340š., 2, 123-124. 
Auf eine weder nachgeburtliche noch im Sinne der Mikrowesen vorgeburtliche Auslegung macht Qurțubī aufmerksam. Danach wurde ein Bund mit dem präexistenten Geist $(r \bar{u} h)_{)}$des Menschen geschlossen. „Gott brachte die Geister hervor, bevor er die Leiber erschuf, und legte in sie eine Erkenntnis, durch die sie erkannten, was er zu ihnen sagte ${ }^{\text {(119 }}$ ). Diese Deutung kann sich auf eine alte Autorität, den Koranausleger aus der Nachfolgegeneration Muhammad b. Ka'b b. Sulaym al-Quraẓī (gest. 118/ 736), berufen ${ }^{120}$ ). Bei Gunayd klingt sie an, wenn er den präexistenten Geist sprechen läßt. Zu Sure 7, 172 vermerkt er: „Wer hat denn Antwort gegeben, wenn nicht die Geister, die bekundeten, daß die Allmacht ins Werk gesetzt und der Wille (Gottes) vollzogen wird?"121) Nach einem Hinweis 'Umar as-Suhrawardīs hat auch Abū Sa'ìd al-Hुarrāz (gest. 277/ 890-1) das $J a$ des Bundes durch die Geister sprechen lassen ${ }^{122}$ ). Nizām addīn an-Naysābūrī al-A'rağ meint, für die Vertreter dieser Ansicht sei das Bekenntnis eine notwendige Eigenschaft des Geistes. Sie sagen: „Die Geister der Menschen existieren vor den Leibern, und das Bekenntnis zur Existenz Gottes ist eine notwendige Eigenschaft ihres Wesens und ihrer Wirklichkeit, und es bedarf keiner Aneignung und keines Suchens, um dieses Wissen zu gewinnen. Doch nachdem die Geister an die Leiber gekettet sind, lenkt sie die Ankettung vom Gegenstand ihres Wissens ab, so daß sie bald durch Erinnerung und Ermahnung sich zurückbesinnen, bald nicht ${ }^{\text {“123}}$ ). Im Zusammenhang mit der Frage, ob der Geist vor oder nach dem Leib erschaffen wurde, hat auch Ibn Qayyim al-Ğawziya (gest. 751/1350) verschiedene Meinungen zu Sure 7, 172 und den entsprechenden Hadīten angeführt $\left.{ }^{124}\right)$. Schließlich stellt er selbst fest: „Auf jeden Fall beweist der Vers nicht, daß die Geister vor den Leibern erschaffen wurden. Er beweist höchstens, daß die Formen und Urbilder der Menschen in Gestalt von Mikrowesen herausgenommen und zum Sprechen gebracht und dann wieder zu ihrem Ursprung zurückgeführt wurden, falls die diesbezügliche Überlieferung echt ist. Richtig ist indessen, daß die Vorausbestimmung und die Teilung der Menschen in Unselige und Selige festgestellt wird. ${ }^{125}$ ).

Der schiitische Gelehrte Muḥammad b. al-Murtaḍā al-Kāšānī, bekannt als Muḥsin-i Fayḍ (gest. 1090/1679-80), versuchte noch eine andere

$\left.{ }^{119}\right)$ Qurțubī 7, 314, 11-13.

120) Tabarī 13, Nr. 15376; Suyūțī, Ad-durr al-manțūr 3, 141, 28-29.

$\left.{ }^{121}\right)$ Sarrāy̆, Al-luma', ed. Nicholson, 29, 16-17; dazu Rasā’il al-Ğunayd 57.

${ }^{122)}$ 'Awārif al-ma'ārif, kap. 56, 8.

$\left.{ }^{123}\right)$ Naysābūrī 9, 83.

$\left.{ }^{124}\right)$ Ibn Qayyim al-Ğawzìya, Kitāb ar-rūh, Ḥaydarābād 1357, 192-210.

${ }^{125)}$ Kitāb ar-rūh 211. 
Deutung. Er brachte den Korantext mit den Überlieferungen in Einklang, indem er das Geschehen nicht in eine uranfängliche Mikrowelt und nicht ins Diesseits verlegte, sondern in eine höhere Seinswelt, die Welt der Wirklichkeiten oder der Urvernunft oder die Welt der Wesenheiten oder der Urbilder. Seine Auslegung: „Er nahm aus ihren Lenden ihre Nachkommenschaft, wie sie nacheinander Generation um Generation geboren werden, heraus. Das heißt: Er streute ihre Wirklichkeiten (haquäiqahum) vor seinem Wissen hin und ließ die Wirklichkeiten mit der Zunge der Fähigkeit ihres Wesens und der Anlage ihres Selbst sprechen und gegen sich selbst zeugen: Bin ich nicht euer Herr? Sie sagten: Ja, wir bezeugen es. Das heißt: Er stellte ihnen die Beweise für sein Herrsein auf und bildete in ihrem Verstand etwas, was sie veranlaßte, dieses zu bekennen, so daß sie gleichnishaft wie Zeugen wurden. Dem ähnlich ist sein Wort: Wenn wir eine Sache wollen, brauchen wir ihr nur zu sagen: Sei!, dann ist sie (Sure 16, 40), und sein Wort: Und er sagte zu ihm (dem Himmel) und zur Erde: Kommt her, freiwillig oder widerwillig! Sie sagten: Wir kommen freiwillig (Sure 41, 11). Es ist aber klar, daß es da keine Rede gab. Das ist nur eine gleichnishafte Gestaltung der gemeinten Sache. Dies geschah, während sich ihr Selbst in den zur Urvernunft gehörigen ('aqlīa) Lenden ihrer Väter und seinem Urquell befand. Das heißt: Er schaute auf sie, indes sie subtile Realitäten $\left(d a q \bar{a}^{\prime} i q\right)$ in jenen Wirklichkeiten waren. Und jene Väter bezeichnete er als Rücken $(z u h \bar{u} r)$, weil jeder von ihnen ein Rücken (zahr) oder eine Gruppe von Individuen in Erscheinung bringend (muzahhir) ${ }^{126}$ ) oder vor ihm erscheinend ( $z \bar{a} h i r)$ ist, da jeder eine geistige, lichthafte, durch sein Wesen erscheinende Gestalt ist. Und er ließ sie gegen sich selbst zeugen, das heißt: Er verlieh ihnen in diesem wahrnehmungshaften, geistigen Entstehen das Zeugesein ihres urvernunfthaften Wesens und lichthaften Seins, so daß sie mit jenen urvernunfthaften Fähigkeiten die Anrede Bin ich nicht euer Herr? so hörten, wie man eine Anrede in der diesseitigen Wohnung mit diesen körperlichen Fähigkeiten hört, und sie sagten mit der Zunge jener Urvernunft: ' $J a$, du bist unser Herr, der uns ein heilig erhabenes, göttliches Sein (wü̆ūdan qudsìyan rabbānìyan) verliehen hat. Wir haben dein Wort gehört und auf deine Anrede geantwortet.' - Nicht unwahrscheinlich ist auch, daß dieses Sprechen mit der wesenheitshaften (malakūt $\bar{\imath}$ ) Zunge in der Welt der Urbilder geschah, die diesseits (oder: hinter, dūna) der Urvernunft liegt. Denn jedem Ding ist eine Wesenheit (malakūt) in jener Welt eigen, wie Gott angedeutet hat in seinem Wort: Gepriesen sei er, in dessen Hand die Wesenheit aller Dinge liegt (Sure 36, 83). Die Wesenheit ist das Innere des irdischen Seins, sie ist ganz Leben, und jedes Atom besitzt eine

126) Muzahhir, laut Text mit tašdìd, also nicht muz̧hir oder maz̧har. 
wesenheitshafte Zunge, die Gottes Preis und Ruhm und Einheit und Lob ausspricht. Mit dieser Zunge sprachen die Steine in der Hand des Propheten ${ }^{127}$ ), mit ihr wird die Erde am Tag der Auferstehung sprechen an jenem Tag wird sie aussagen, was sie zu berichten hat (Sure 99, 4) -, und mit ihr werden die Glieder sprechen: Gott, der allem Sprache verleiht, hat uns sprechen lassen (Sure 41, 21)“128).

Diese Übersicht mag genügen. Sie hat gezeigt, daß die Ausleger sich keineswegs auf einen Urvertrag mit Mikrowesen geeinigt haben. Von den Mu'taziliten und gewissen Schiiten wurde er grundsätzlich abgelehnt, für die Deutung von Sure 7, 172-173 auch von vielen Sunniten. Für diese Koranstelle bietet er nur eine unter mehreren Möglichkeiten der Auslegung. Auch andere, nicht in der Präexistenz geschlossene „Urverträge“ erschließt man aus dem Koran. Die Schöpfung der Urnatur, in die die Erkenntnis des einen Herrn eingesenkt ist, ist eine Art Naturvertrag, der eine naturrechtliche Pflicht zur Anerkennung und Verehrung des einen Gottes begründet. Ein Urvertrag ist auch die von Muhsin-i Fayḍ beschworene, in der Welt der Urbilder oder der Wesenswelt eingegangene wesenhafte Bindung. Auch die Belehrung durch Propheten wurde wie eine Verpflichtung durch einen Vertrag gesehen, auf den unser Koranvers hinweise. Und schließlich ist auch ein Vertrag mit einem begrenzten Teil der Menschheit für dessen Nachfahren ebenso präexistentiell wie deren Verpflichtung durch den die gesamte Menschheit bindenden Urvertrag. Die Auslegungen von Sure 7, 172-173 sind recht unterschiedlich, das Gemeinsame aller Denkrichtungen aber ist eine mahnende Erinnerung an die Verpflichtung, sich zu dem einen Gott als dem alleinigen Herrn zu bekennen.

\section{Die wichtigsten Abkürzungen}

Abu l-futūḥ: Abu l-futūḥ Gamāl ud-dīn-i Rāzī. Rawh ul-ğinān wa rūḥ ul-ğanān. Teheran $1382 \mathrm{ff}$.

Abu s-Su'ūd: Abu s-Su'ūd Muhammad b. Muhammad al-'Imādī. At-tafsīr = Iršăd al'aql as-salìm ilā mazāyā al-Qur'ān al-karìm. 1-5. Kairo 1372/1952.

Bayḍ̂āī: Abū Sa'īd Nāşir ad-dīn 'Abdallāh b. 'Umar. Anwār at-tanzīl wa-asrār atta'wīl. Ed. H. O. Fleischer. 1-2. Leipzig 1846-1848.

Gurḡānī: Abu l-mahāāin al-Husayn b. al-Ḥasan al-Gurḡānī. Ğilà ul-ad̄ān wa-ğală $u l$-ahzzān = Tafsìr-i Gāzur. 1-10. Teheran 1378q./1337s.

Ibn al-Ğawzī: Abu l-farağ 'Abd ar-Raḥmān b. al-Gawzì. Zād al-masīr fĩ 'ilm attafsīr. 1-9. Damaskus 1384-88/1964-68.

$\left.{ }^{127}\right)$ Yūsuf b. Ismā'ìl an-Nabhānī, Hư̆ğat Allāh 'alā al-'ālamīn fì mu'ğizāt Sayyid al-mursalīn, Beirut o. J., 446-447.

${ }^{128)}$ Al-Fayḍ al-Kās̄ānī, Aş-șāfĩ fĩ tafsīr al-Qur'ān, Teheran 1384, 1, 624-625. 
Ibn Kațīr: 'Imād ad-dīn Abu l-fidā' Ismāîil b. Kațīr al-Qurašī ad-Dimašqī. Tafsīr al-Qur'ān al-'azìm. 1-4. Kairo o.J.

Kulīnī: Abū Ğa'far Muhammad b. Ya'qūb b. Ishạā al-Kulīnī ar-Rāzì. Al-uşūl min al-Käfĩ. Ed. 'Alī Akbar al-Gaffārì. 1-2. Teheran 1381.

Maqdisī: Al-Muțahhar b. Țāhir al-Maqdisī. Kitāb al-bad wa-t-ta’rīh li-Abī Zayd Ahmad b. Sahl al-Balhīi. Ed. C. Huart. Paris 1899. Nachdruck Bagdad 1962.

Murtaḍā: 'Alī b. al-Ḥusayn al-Mūsawī al-'Alawī aš-Šarî́ al-Murtaḍā. Gurar alfawā'id wa-durar al-qalä’id = Al-amālī. Ed. Muḥammad Abu l-Faḍl Ibrāhīm. 1-2. Kairo 1373/1954.

Naysābūrī: Nizāam ad-dīn al-Ḥasan b. Muhammad b. al-Ḥusayn al-Qummī anNaysābūrī. Ġarā'ib al Qur'ān wa-raḡà'ib al-Furqān. Ed. Ibrāhīm 'Ațwa 'Iwaḍ. Kairo 1381/1962 ff.

Qurțubī: Abū 'Abdallāh Muhammad b. Ahmad al-Qurțubī. At-tafsīr $=A l-g ̆ a ̄ m i ' ~ l i$ ahkām al-Qur'ān. 1-20. Kairo 1354-69/1935-50.

Rāzì: Faḩr ad-dīn ar-Rāzì. At-tafsīr al-kabīr. 1-32. Kairo 1352/1933ff.

Tabarī: Tafsìr = Ğāmi' al-bayān 'an ta'wīl al-Qur'ān. Ed. Mahmūd Muhammad Šākir und Ahmad Muhammad Šākir. Dār al-ma‘āirif, Kairo $1374 \mathrm{ff}$.

Tabarī, Ta'rīh: Abū Ga'far Muhammad b. Garīr at-Tabarī. Ta'rīh ar-rusul wa-l$m u l \bar{u} k=$ Annales. Ed. de Goeje et alii. Leiden 1879-1901. Photomechanische Wiedergabe Leiden 1964.

Tabrisī: Abū 'Alī al-Faḍl b. al-Ḥasan aț-Tabrisī. Mağma' al-bayān fĩ tafsìr alQurān. 1-30. Beirut 1375-7/1956-7.

Țūsī: Abū Ğa'far Muhammad b. al-Ḥasan aț-Tūsī Šayh aț-ța'ifa. At-tibyān fĩ tafsīr al-Qur'ān. 1-10. Nağaf 1376-83/1957-63.

Zamaȟsarī: Abu l-Qāsim Mahmūd b. 'Umar az-Zamahšarī. Al-kaššăf 'an haqā̉iq at-tanzìl. 1-4. Kairo 1365/1946. 